\title{
Medical audit
}

\section{Management of gallstone disease in the elderly}

\author{
JDR Arthur ${ }^{1}$, PR Edwards ${ }^{2}$, LS Chagla ${ }^{1}$ \\ ${ }^{1}$ Department of Surgery, Whiston Hospital, Prescot, Merseyside, UK \\ ${ }^{2}$ Department of Surgery, Countess of Chester Hospital, Chester, Cheshire, UK
}

\begin{abstract}
Aim: To determine the outcome of management of symptomatic gallstone disease (GSD) in patients aged 80 years or more.

Patients and Methods: A retrospective review of the outcome of 79 patients admitted to 2 district general hospitals with symptomatic GSD over a 1-year period was undertaken. Patients were grouped according to method of management: non-operative, ERCP, and cholecystectomy. POSSUM scores for the ERCP and cholecystectomy groups were calculated and observed, and predicted outcome compared.

Results: Obstructive jaundice and biliary colic were the most common presenting symptoms. Each patient had been admitted at least once before the study period (median, 2; range, 1-3). Outcomes are detailed in Table 1. Non-operative management failed in 18 of 23 patients, with $17.4 \%$ mortality. ERCP was successful in 40 of 47 patients with 3 complications ( 0.24 of predicted) and no mortality. In all, 11 laparoscopic and 12 open cholecystectomies were performed with 6 complications and 1 mortality ( 0.95 and 0.83 of predicted, respectively): 4 complications and the only death occurring after emergency cholecystectomy.
\end{abstract}

Table 1 Outcomes

\begin{tabular}{lcccl}
\hline Management & Number & Mortality & Morbidity & Outcome \\
\hline Non-operative & 23 & 4 & 9 & 5 OK, 13 re-admitted, 4 still symptomatic \\
ERCP & 47 & 0 & 3 & 1 PTC, 6 operated \\
Operative & 23 & 1 & 6 & \\
\hline
\end{tabular}

Conclusions: This study suggests that recurrent GSD in elderly patients managed non-operatively may have fatal outcome. Elective cholecystectomy has acceptable morbidity and mortality in this age group and there is often ample opportunity to avoid emergency surgery, but a prospective randomised study is required to improve clinical algorithms.

Key words: Gallstone disease - Elderly - Management

$\mathrm{T}$ The latter half of the 20th century saw an increase in the incidence of gallstone disease (GSD) in Britain. This was partly due to the increasing age of the population. It is estimated that up to $28 \%$ and $42 \%$ of men and women, respectively, aged $80-89$ years have gallstones. Of these, $30 \%$ are symptomatic, and are seen by surgeons around

Correspondence to: JDR Arthur MRCS, c/o Mr Brough's Secretary, Department of Surgery, Macclesfield District General Hospital, Victoria Road, Macclesfield, Cheshire SK10 3BL, UK 
the country. ${ }^{1-3}$ As the average age of the population increases, it is likely that more elderly patients with GSD will be seen. Sometimes, purely due to advanced age but often due to coexisting medical disease, such elderly patients are considered high-risk for anaesthesia and surgery. For many surgeons, it has become customary to seek non-operative modes of management, perhaps denying this group of patients an interventional option. In the younger age group, cholecystectomy - either open (OC) or laparoscopic (LC) - is the procedure of choice in patients with cholecystolithiasis whereas in choledocholithiasis, endoscopic retrograde cholangiopancreatography (ERCP) followed by cholecystectomy with or without common bile duct (CBD) exploration remain the options for treatment.

Since its introduction, LC has rapidly become the most commonly performed procedure for symptomatic cholecystolithiasis in healthy individuals. It has been shown to provide the same benefits of shorter hospital stay and better pain control to elderly patients as to the young. Age alone should not be a contra-indication to LC. ${ }^{4}$ Occasionally, the procedure has to be converted to an open procedure, especially in emergencies and in those with complicated disease. A review of 283 patients suggested that elderly patients with uncomplicated disease were excellent candidates for LC while those with complicated disease were more likely to be converted to OC. ${ }^{5}$ It has been suggested that early laparoscopic intervention, before the onset of complications, both medical and gallstone-related, is safe and may result in better outcome for the elderly at lower $\operatorname{cost}^{6}$ The National Commission for Enquiry into Perioperative Deaths (NCEPOD), however, cautions that highrisk patients (and elderly patients more often than not fall into this category) may not be able to tolerate the stress of required anaesthesia and pneumoperitoneum (summary of 1996/97 Report, published November 1998).

ERCP has many recognised associated complications including ERCP-induced pancreatitis, yet it is still the standard technique for the treatment of choledocholithiasis and CBD obstruction. In the elderly, successful ERCP with sphincterotomy with or without stenting may obviate the need for further biliary tract surgery, 7,8 though, as suggested by Targarona et al., cholecystectomy with CBD exploration is preferable to sphincterotomy as definitive treatment. In a randomised trial of 98 patients undergoing either OC and duct exploration or ERCP and sphincterotomy, they found $20 \%$ of the latter group representing with further biliary symptoms after a mean follow-up period of 17 months, $70 \%$ of whom needed biliary surgery. ${ }^{9}$ Hammarstrom et al. also found both procedures equally effective in the elderly in the long term, though suggesting surgery to be the better option due to significantly increased mortality from heart disease in those having ERCP compared to cholecystectomy. ${ }^{10}$
Minimal intervention utilising percutaneous cholecystostomy (PC) has been suggested as a suitable alternative to cholecystectomy in the critically ill patient. It has a low procedure-related morbidity and mortality, and the literature available suggests that there is early resolution of acute symptoms. There is, however, a paucity of literature on the subject and PC may only be permanent treatment in patients with acalculous cholecystitis and in those whose gallbladder is shrivelled and fibrosed following PC. However, in patients with a patent cystic duct, the gallbladder may recover and continue to cause problems. These patients may need to go on to definitive treatment. ${ }^{11-19}$

The aim of this study was to audit our management of GSD in the elderly, reviewing the outcome of non-operative, endoscopic and surgical management of patients presenting with complications of their gallstones.

\section{Patients and Methods}

Using the relevant diagnostic and treatment codes, we identified all patients aged 80 years or more who had been admitted with symptomatic GSD over a 1-year period (1997) to two district general hospitals (DGHs) in the Merseyside region. Patients were classified into 3 groups according to their primary management strategy: (i) those managed nonoperatively; (ii) those undergoing ERCP; and (iii) those who had cholecystectomy with or without CBD exploration. For all patients managed non-operatively, the decision was taken solely by the managing consultant often in consultation with senior anaesthetists and after discussion with patient and family where possible. The decision was based on age and severity of co-existing medical disease. No formal physiological scoring was, however, performed at the time. Data collected included presenting complication of GSD, number of previous admissions with GSD, and outcome of each modality of treatment. Physiological and operative severity score (POSSUM) for enumeration of morbidity (M) and mortality (D) analysis of patient variables was used to calculate expected outcome of management for the ERCP and cholecystectomy groups and this was compared to the observed outcome $\left(0: \mathrm{E}^{\mathrm{M}}\right.$ and $\left.0: \mathrm{E}^{\mathrm{D}}\right)$. ERCP qualified as a surgical procedure as all patients had sphincterotomies.

\section{Results}

A total of 79 patients were identified, with a median age of 85 years (range, 80-97 years) and a male-to-female ratio of 1:1.82. Patients were grouped according to their final working diagnoses and initial management plan after clinical examination, findings on radiological investigation, and liver function biochemical tests (LFTs). Each patient's course of management, outcomes and complications was 


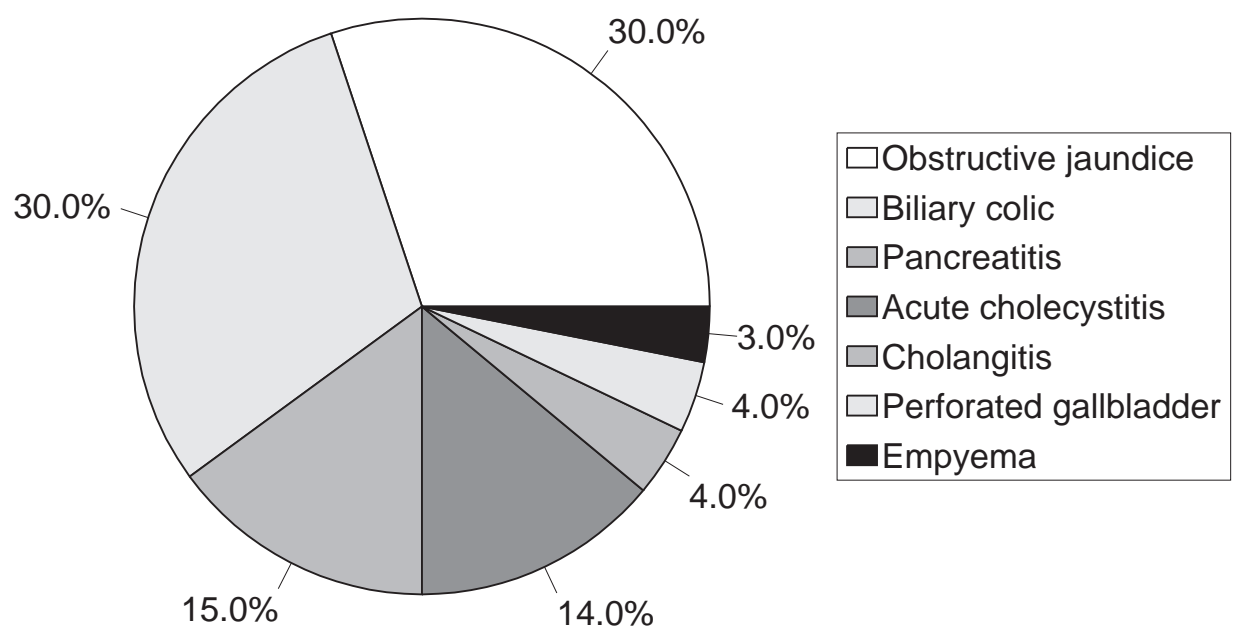

Figure 1 Presenting diagnoses.

documented. Each patient's case sheet entries relevant to gallstone disease for up to 12 months after initial presentation were studied.

Presenting diagnoses are as shown in Figure 1.

\section{Group 1: non-operative management}

This group consisted of 23 patients with a median physiological score of 19 (range, 17-30). All patients had presented with gallbladder-only pathology (stones or sludge in gallbladder, radiological evidence of cholecystitis, normal LFTs, no radiological evidence of CBD dilatation or CBD stones).

The outcome of management for these patients, 12 months from time of initial treatment, is shown in Figure 2. One patient perforated on the 4 th day into trial of non-

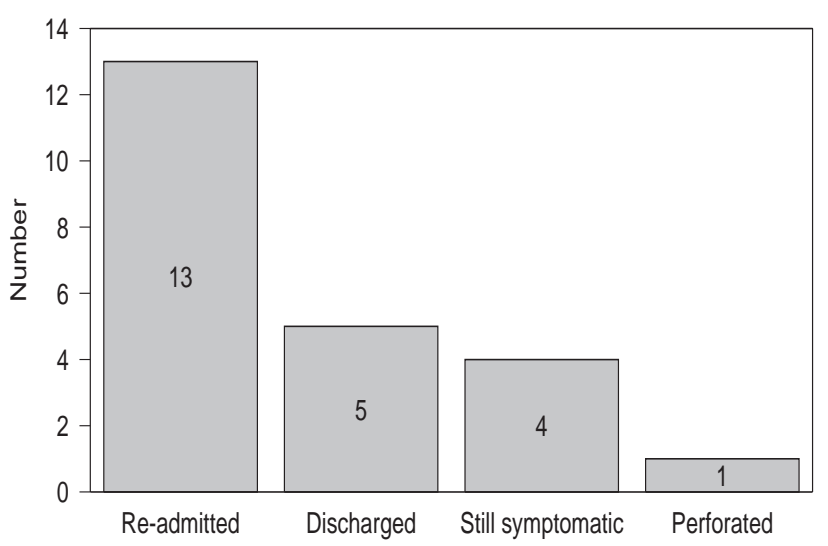

Figure 2 Outcome of non-operative treatment.
Table 2 Morbidity and mortality

\begin{tabular}{|c|c|c|}
\hline Con & ications $(n)$ & Deaths $(n)$ \\
\hline \multicolumn{3}{|l|}{ Non-operative } \\
\hline Pancreatitis & - & 2 \\
\hline Cholangitis & - & 1 \\
\hline Empyema & - & 1 \\
\hline \multicolumn{3}{|l|}{ ERCP } \\
\hline Haemorrhage & 1 & - \\
\hline Pancreatitis & 2 & - \\
\hline \multicolumn{3}{|l|}{ Cholecystectomy } \\
\hline Chest infection & 2 & - \\
\hline Wound infection & 2 & - \\
\hline Myocardial infarction & 1 & 1 \\
\hline $\begin{array}{l}\text { Pseudomembranous } \\
\text { Colitis }\end{array}$ & 1 & - \\
\hline
\end{tabular}

operative management and 5 patients had been discharged from care. All the remaining 17 patients had been readmitted at least once during the follow-up period, 4 of whom were still symptomatic at the time of this study but had refused surgery. Five patients eventually had cholecystectomy with good outcome. One patient needed ERCP having re-presented with CBD stone complications. There were 4 deaths $(17.4 \%)$, all occurring in re-admitted patients. Three of these occurred in patients who had been seen initially with gallbladder-only pathology, but had been readmitted with complications of choledocholithiasis (Table 2). Reasons for re-admission and causes of death are shown in Tables 1 and 2, respectively. Overall, non-operative management of gallbladder-only pathology failed in 18 patients $(78.3 \%)$. 
Table 3 Indications for ERCP

\begin{tabular}{lc}
\hline $\begin{array}{l}\text { Clinical diagnosis, biochemical and } \\
\text { radiological investigations }\end{array}$ & Patients $(n)$ \\
Obstructive jaundice & 24 \\
$\begin{array}{l}\text { Gallstone pancreatitis } \\
\text { Cholangitis }\end{array}$ & 3 \\
$\begin{array}{l}\text { Acute cholecystitis with deranged LFT } \pm \text { dilated } \\
\text { CBD on ultrasound scan }\end{array}$ & 3 \\
$\begin{array}{l}\text { Biliary colic with dilated CBD and deranged LFT } \\
\text { Gallbladder dyspepsia on initial admission, }\end{array}$ & 4 \\
$\begin{array}{l}\text { managed conservatively, but re-admitted with } \\
\text { obstructive jaundice }\end{array}$ & 1 \\
\begin{tabular}{l} 
Total \\
\hline
\end{tabular} & 47 \\
\hline
\end{tabular}

Table 4 Cholecystectomy group; reasons and indications

\begin{tabular}{lc}
\hline Reasons and indications & Patients $(n)$ \\
\hline Failed ERCP who had OC and CBD exploration & 7 \\
$\begin{array}{l}\text { Patients considered fit for surgery at initial } \\
\text { admission (interval LC) }\end{array}$ & 5 \\
$\begin{array}{l}\text { Patients initially considered unfit but who wanted } \\
\text { surgery due to repeated admissions and persisting }\end{array}$ & 6 \\
$\begin{array}{l}\text { symptoms (interval LC) } \\
\text { Peritonitis due to perforated gallbladder } \\
\text { (emergency cholecystectomy) }\end{array}$ & 3 \\
Urgent cholecystectomy for empyema & 2 \\
Total & 23 \\
\hline
\end{tabular}

Group 2: ERCP + sphincterotomy $( \pm$ stone extraction \pm stenting

Indications for ERCP in the patients in this group are shown in Table 3. The 47 patients who had ERCP had a physiological score of 19 (range, 16-31). The procedure was successful in $40(85.1 \%)$ patients. At follow-up, these patients were asymptomatic and remained so for a mean follow-up of 12 months. Of 7 (14.9\%) failed ERCPs, 6 went on to have elective $\mathrm{OC}$ and CBD exploration and 1 patient underwent combined ERCP and percutaneous transhepatic cholangiography and duct stenting. There was no mortality after ERCP; however, 3 (6.4\%) complications occurred (Table 2).

\section{Group 3: cholecystectomy}

There were 11 LCs and 12 OCs (6 elective and 6 urgent/ emergency). Diagnoses and circumstances leading to cholecystectomy are summarised in Table 4. None of the LCs needed conversion to OC. Median physiological score was once again 19 (range, 17-27). Median previous admissions was 2 (range, 1-3). Postoperative complications occurred in $6(26.1 \%)$ patients and there was only 1 death $(4.3 \%)$. Four of these complications and the mortality occurred in patients having emergency surgery $(66.7 \%$ and $16.7 \%$, respectively). Median length of postoperative stay was 9 days (range, 5-17 days).

\section{Observed:expected (derived from POSSUM) outcome}

\section{ERCP}

Median predicted risks of morbidity and mortality were $27.5 \%$ (range, $11.7-59.4 \%$ ) and $4.9 \%$ (range, $2.1-13.1 \%$ ), respectively. Comparison to observed morbidity of $6.7 \%$ gave an $\mathrm{O}: \mathrm{E}^{\mathrm{M}}$ of 0.24 . There was no observed mortality.

\section{Cholecystectomy}

Median predicted risk of morbidity and mortality were $27.5 \%$ (range, $21.1-73.1 \%$ ) and 5.2\% (range, 3.9-26.7\%), respectively. With an observed morbidity and mortality of $26.1 \%$ and $4.3 \%$, the $\mathrm{O}: \mathrm{E}^{\mathrm{M}}$ and $\mathrm{O}: \mathrm{E}^{\mathrm{D}}$ ratios were 0.95 and 0.83 , respectively. Actual deaths were, therefore, less than expected deaths.

\section{Discussion}

\section{Choledocholithiasis}

The optimum management of choledocholithiasis is ERCP with sphincterotomy and duct clearance. The procedure is technically demanding and associated with significant complications. It should be undertaken by either a trained surgeon or physician. Although in this study the 2 endoscopists were one of each of the above, successful ERCP and duct clearance was lower than that quoted in the literature. ${ }^{9,20-26}$ Excluding failures, the complication rate in this small series of ERCP was minimal. All of the successfully treated patients, however, remained asymptomatic at the end of the study. Hammarstrom et al. had a longer follow-up and though ERCP reduced the recurrence of gallstone pancreatitis, it did not prevent late biliary complications. ${ }^{27}$ Our study indicates that ERCP for the management of choledocholithiasis in the over 80 year olds may be the only intervention needed to achieve an asymptomatic state, accepting, of course, that our mean follow-up was relatively short.

\section{Cholecystolithiasis}

A more difficult issue, however, is the management of patients presenting with cholecystolithiasis and its complications. Anecdotally, many surgeons treat elderly patients presenting with biliary colic and acute cholecystitis expectantly and do not routinely offer 
elective surgical intervention. Our study would suggest that this has been the policy adopted by the surgeons in the DGHs concerned. It should be emphasised that some patients declined the offer of surgery, although it is uncertain as to how they were counselled. We were surprised at the hitherto undocumented high re-admission rate and the severity of the complications with which the patients were re-admitted. Choledocholithiasis-related complications occurring after previous admission for cholecystolithiasis were associated with high mortality. As our results show, $75 \%$ of deaths in the non-interventional group were in such progressed patients. These deaths may have been avoided if early planned surgery had been undertaken. In our group of operated patients, the overall outcome was comparable to that in the literature. ${ }^{28,29}$ The observed morbidity and mortality was less than that predicted by POSSUM, possibly reflecting the small group size. Even if this group had had a slightly higher mortality rate as predicted, their outcome would still have been better than the non-operated group. Elderly patients who require emergency cholecystectomy tend to do poorly compared to younger patients, with mortality rates of $6-15 \%$ reported. ${ }^{30}$ As well as reflecting this fact, our study also shows the relative safety of planned cholecystectomy compared to emergency procedures. As all of the patients operated on had been admitted at least once prior to surgery, it is reasonable to suggest that there is often ample opportunity to plan an elective procedure in these patients, thus avoiding the unwanted outcomes of emergency surgery.

Patients with only cholecystolithiasis were offered LC, others proceeding directly to OC. None of the patients undergoing LC were converted to OC in comparison to some reports where conversion rates of up to $50 \%$ were noted for this age group. ${ }^{4,5,31}$ Fried et al. ${ }^{32}$ found a global conversion rate of $5.4 \%$, reporting that patients aged 65 years or more were more than 2 -fold more likely to be converted to OC.

Whilst it may not be justified to compare statistically the operated and non-operated groups, it would seem that non-operative management may be associated with higher morbidity and mortality as shown by our results. It seems, therefore, that patients presenting with cholecystolithiasis should be counselled in respect of the high incidence of complications associated with non-operative management. Early elective cholecystectomy should prevent these complications and is itself associated with a relatively small and acceptable morbidity and mortality.

\section{Conclusions}

GSD in the elderly is a recurrent condition with worsening complications at repeated presentations. Despite advanced age and co-existing medical illness, cholecystectomy is safe and should be offered to patients when symptomatic. Elective operative intervention is preferable to emergency surgery and should be considered at initial rather than subsequent presentation. ERCP with sphincterotomy and stone extraction may be the only treatment required for patients with choledocholithiasis who are not fit for surgery. This study questions the practice of non-operative management of GSD and a prospective randomised trial is required to guide future treatment policy.

\section{References}

1. Bateson MC. Gallbladder disease. BMJ 1999; 318: 1745-8.

2. Bates T, Hamm M, Lowe D, Lawson C, Padle N. Longitudinal study of gallstone prevalence at necropsy. Gut 1992; 33: 103-7.

3. Bateson MC. Gallbladder disease and cholecystectomy rates are independently variable. Lancet 1984; 2 : 621-4.

4. Saxe A, Lawson J, Phillips E. Laparoscopic cholecystectomy in patients aged 65 or older. J Laparoendosc Surg 1993; 3: 215-9.

5. Magnuson TH, Ratner LE, Zenilman ME, Bender JS. Laparoscopic cholecystectomy: applicability in the geriatric population. Am Surg 1997; 63: 91-6.

6. Maxwell JG, Tyler BA, Maxwell BG, Brinker CC, Covington DL. Laparoscopic cholecystectomy in octogenarians. Am Surg 1998; 64: 826-31.

7. Siegel JH, Kasmin FE. Biliary tract diseases in the elderly: management and outcomes. Gut 1997; 41: 433-5.

8. Law NM, Lim CC, Yap CK, Chong R, Ng HS, Cheng J. Endoscopic stenting in the management of biliary stones. Singapore Med J 1996; 37 475-8.

9. Targarona EM, Ayuso RM, Bordas JM, Ros E, Pros I, Martinez J et al. Randomised trial of endoscopic sphincterotomy with gallbladder left in situ versus open surgery for common bile duct calculi in high-risk patients. Lancet 1996; 347: 926-9.

10. Hammarstrom LE, Holmin T, Stridbeck H, Ihse I. Long-term followup of a prospective randomised study of endoscopic versus surgical treatment of bile duct calculi in patients with gallbladder in situ. $\mathrm{Br} J$ Surg 1995; 82: 1516-21.

11. Berber E, Eingle KL, String A, Garland AM, Chang G, Macho J et al. Selective use of tube cholecystostomy with interval laparoscopic cholecystectomy in acute cholecystectomy. Arch Surg 2000; 135: 341-6.

12. Patel M, Miedema BW, James MA, Marshall JB. Percutaneous cholecystostomy is an effective treatment for high-risk patients with acute cholecystids. Am Surg 2000; 66: 33-7.

13. Davis CA, Landercasper J, Gundersen LH, Lambert PJ. Effective use of percutaneous cholecystostomy in high-risk surgical patients: techniques, tube management and results. Arch Surg 1999; 134: 727-31.

14. Boggi U, Di Candio G, Campatelli A, Oleggini M, Pietrabissa A, Fillipord F et al. Percutaneous cholecystostomy for acute cholecystitis in critically ill patients. Hepatogastroenterology 1999; 46: 121-5.

15. Kiviniemi H, Makela JT, Autio R, Tikkakoski T, Leinonen S, Siniluoto $\mathrm{T}$ et al. Percutaneous cholecystostomy in acute cholecystitis in highrisk patients: an analysis of 69 patients. Int Surg 1998; 83: 299-302.

16. Wong SK, Yu SC, Lam YH, Chung SS. Percutaneous cholecystostomy and endoscopic cholecystolithotripsy in the management of acute cholecystitis. Surg Endosc 1999; 13: 48-52.

17. Lee KT, Wong SR, Cheng JS, Ker CG, Sheen PC, Liu YE. Ultrasoundguided percutaneous cholecystostomy as an initial treatment for acute cholecystitis in elderly patients. Dig Surg 1998; 15: 328-32.

18. Sugiyama M, Tokuhara M, Atomi Y. Is percutaneous cholecystostomy 
the optimal treatment for acute cholecystostomy in the very elderly? World J Surg 1998; 22: 459-63.

19. Liu CL, Lo CM, Fan ST. Acute biliary pancreatitis: diagnoses and management. World J Surg 1997; 21: 149-54.

20. Uomo G, Manes G, Laccetti M, Cavallera A, Rabitti PG. Endoscopic sphincterotomy and recurrence of acute pancreatitis in gallstone patients considered unfit for surgery. Pancreas 1997; 14: 28-31.

21. Siegel JH, Kasmin FE. Biliary tract diseases in the elderly: management and outcomes. Gut 1997; 41: 433-5.

22. Cotton PB, Vallon AG. British experience with duodenoscopic sphincterotomy for removal of bile duct stones. Br J Surg 1981; 68: 373-5.

23. Reiter JJ, Bayer HP, Mennicken C, Manegold BC. Results of endoscopic papillotomy: a collective experience from nine endoscopic centres in West Germany. World J Surg 1978; 25: 505-11.

24. Escourrou J, Cordova JA, Lazorthes F, Frexinos J, Ribet A. Early and late complications after endoscopic sphincterotomy for biliary lithiasis with and without the gallbladder in situ. Gut 1984; 25: 598-602.
25. Safrany L, Cotton PB. Endoscopic management of choledocholithiasis. Surg Clin North Am 1982; 62: 825-36.

26. Hammarstrom LE, Stridbeck H, Ihse I. Effect of endoscopic sphincterotomy and interval cholecystectomy on late outcome after gallstone pancreatitis. Br J Surg 1998; 85: 333-6.

27. Gonzalez JJ, Sanz L, Grana JL, Bermejo G, Navarrete F, Martinez E. Biliary lithiasis in the elderly patient: morbidity and mortality due to biliary surgery. Hepatogastroenterology 1997; 44: 1565-8.

28. Escarce JJ, Shea JA, Chen W, Qian Z, Schwartz JS. Outcome of open cholecystectomy in the elderly: a longitudinal analysis of 21,000 cases in the prelaparoscopic era. Surgery 1995; 117: 156-64.

29. Glenn F, Hays DM. The age factor in the mortality rate of patients undergoing surgery of the biliary tract. Surg Gynecol Obstet 1955; 100: 11.

30. Tagle FM, Lavergne J, Barkin JS, Unger SW. Laparoscopic cholecystectomy in the elderly. Surg Endosc 1997; 11: 636-8.

31. Fried GM, Clas D, Meakins JL. Minimally invasive surgery in the elderly patient. Surg Clin North Am 1994; 74: 375-86. 